\title{
Surface deterioration of wood plastic composites under outdoor exposure
}

\author{
Kenichi Ebe $\cdot$ Noboru Sekino
}

Received: 22 July 2014/ Accepted: 7 November 2014/Published online: 3 December 2014

(C) The Japan Wood Research Society 2014

\begin{abstract}
Outdoor exposure tests of wood plastic composites (WPCs) were conducted at seven sites in Japan. The tests examined the process of chalking on the surface of the WPCs and the weather factors affecting chalking. Observations using a scanning electron microscope and a polarization optical microscope (POM), analyses of Fourier transform infrared spectroscopy, as well as differential scanning calorimetry showed that the deterioration of both wood and polyolefin elements occurs on the surface of WPCs. The POM observations revealed that surface sanding of WPCs in the manufacturing process promoted more chalking. Furthermore, it became clear that among the weather conditions studied, temperature and global solar radiation had the greatest influence on chalking, as determined from the results of single regression analysis.
\end{abstract}

Keywords WPCs - Outdoor exposure - Polyethylene carbonyl index . Chalking $\cdot$ Weather factor

\section{Introduction}

Recently, wood plastic composites (WPCs) have attracted considerable attention as materials with the combined characteristics of wood and plastic [1, 2]. WPCs are manufactured as easily as plastic, by extrusion molding. In

\footnotetext{
K. Ebe $\cdot$ N. Sekino

Iwate University, Morioka 020-8550, Japan

e-mail: sekino@iwate-u.ac.jp

K. Ebe $(\square)$

Yamagata Research Institute of Technology,

Yamagata 990-2473, Japan

e-mail: ebek@pref.yamagata.jp
}

addition, because ligneous wastes and recycled plastic can be used as raw materials, WPCs are favored from an environmental perspective [3]. In 2010, the global production of WPCs was about 1540000 tons per year, with 980000 tons in the United States, 300000 tons in China, 167000 tons in Europe, and 21000 tons in Japan [4].

As WPCs are primarily used on exteriors, concerns about their water resistance and decay resistance have increased. It is clear that water resistance and decay resistance depend on the proportion of wood in WPCs [57]. Water and decay resistance decline remarkably, especially on the surface of WPCs, when the proportion of wood is more than $50 \%$ [6-8].

Recently, the durability of WPCs has been a topic of growing interest, with several reports on the decrease in strength and surface deterioration [9-11]. A large scale outdoor exposure test is effective for evaluating the influence of weather factors on the durability of wood-based composites [12-14]. However, there have been few examples of such tests using WPCs [15]. Furthermore, little attention has been paid to research on the occurrence of chalking, which is one of the surface deterioration phenomena of WPCs [16]. Chalking is a phenomenon through which powders separate from the surface of WPCs. Chalking is seldom a problem when WPCs are used as decking, because it affects only footwear. So some commercial products of WPCs improved chalking generation using photo stabilizers or reducing wood content of the surfaces. However, the mechanism of chalking has not been cleared.

This study is aimed at explaining the principal causes of chalking in WPCs. Outdoor exposure tests of WPCs were carried out at seven sites in Japan, and the process of chalking with respect to various weather factors was investigated. 


\section{Materials and methods}

\section{Samples}

The raw materials of the WPCs used in this research were building wood waste and recycled plastic (polyolefin). The ratio of wood flours to polyolefin [polyethylene (PE) and polypropylene (PP)] was about 55:45 (w/w). About $5 \%$ of compatibilizers and pigments were added. But any photo stabilizers such as UV absorbers (UVA) or hindered amine light stabilizers (HALS) were not added because of easy generation of chalking. Test specimens used in this study were made by the extrusion method. Sanding was then carried out on the surface of the WPCs to give the appearance of wood. The specimens with a size of 145-174 (longitudinal) $\times 70$ (width) $\times 7 \mathrm{~mm}$ (thickness) were prepared from the $30 \mathrm{~mm}$ thick commercial hollow decks. Polyethylene reference samples, PE-RS (Japan weathering test center $[17,18])$, were prepared to evaluate the oxidation-degradation of polyolefin in WPCs. The PE-RS were exposed outdoors at the same sites that were used for the WPCs outdoor exposure tests.

Outdoor exposure tests at seven sites in Japan

The WPCs and PE-RS were subjected to outdoor exposure tests at seven sites in Japan (Fig. 1): Sapporo $\left(43^{\circ} \mathrm{N}\right.$, $\left.141^{\circ} \mathrm{E}\right)$, Yamagata $\left(38^{\circ} \mathrm{N}, 140^{\circ} \mathrm{E}\right)$, Akishima $\left(36^{\circ} \mathrm{N}\right.$, $\left.139^{\circ} \mathrm{E}\right)$, Takaoka $\left(37^{\circ} \mathrm{N}, 137^{\circ} \mathrm{E}\right)$, Kure $\left(34^{\circ} \mathrm{N}, 133^{\circ} \mathrm{E}\right)$, Kochi $\left(34^{\circ} \mathrm{N}, 134^{\circ} \mathrm{E}\right)$, and Miyazaki $\left(32^{\circ} \mathrm{N}, 131^{\circ} \mathrm{E}\right)$. The annual average temperature, annual sunlight hours, and annual precipitation are listed in Table 1 . These data were
Fig. 1 Map of the outdoor exposure test sites in Japan

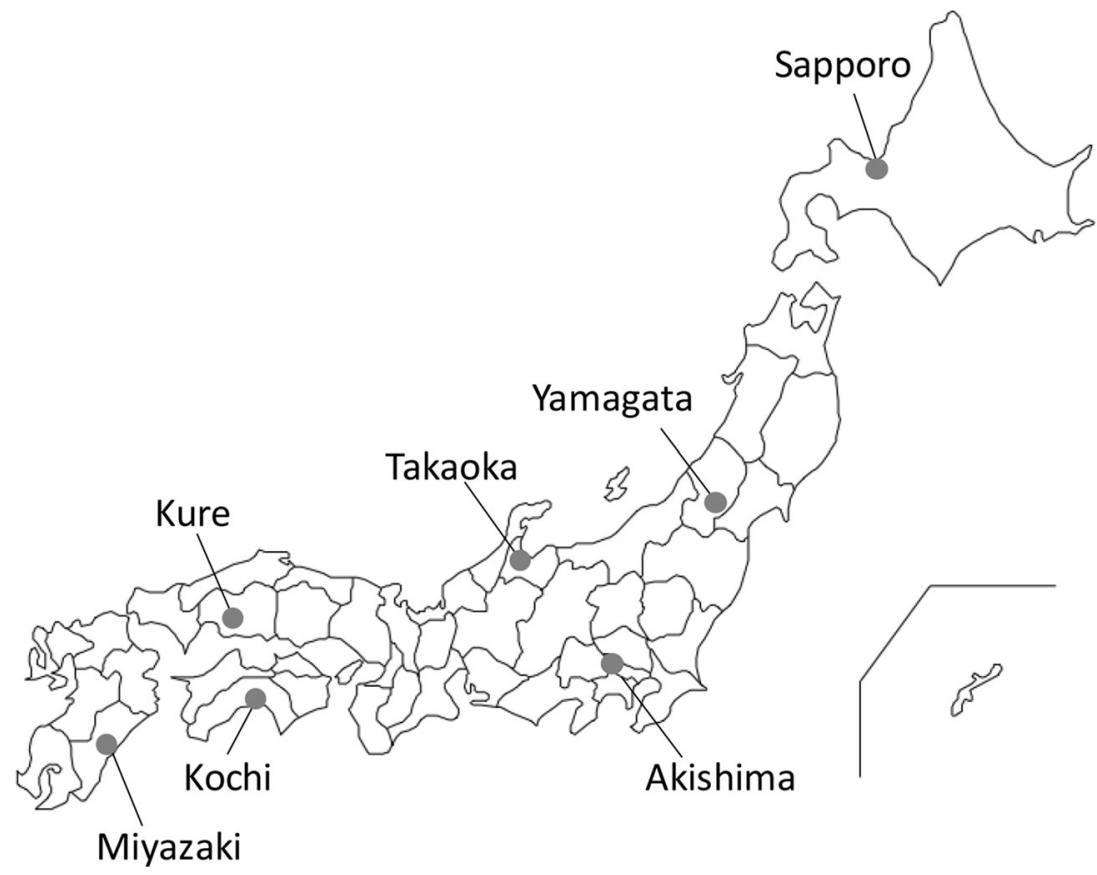

Table 1 Weather conditions of the seven test sites in Japan

a Data are average values of the past 30 years (1983-2012)

\begin{tabular}{llllclll}
\hline $\begin{array}{l}\text { Outdoor } \\
\text { exposure } \\
\text { test sites }\end{array}$ & $\begin{array}{l}\text { Meteorological } \\
\text { observation sites } \\
\text { of the Japan } \\
\text { meteorological } \\
\text { agency }\end{array}$ & $\begin{array}{l}\text { North } \\
\text { latitude } \\
\left({ }^{\circ}\right)\end{array}$ & $\begin{array}{l}\text { East } \\
\text { longitude } \\
\left({ }^{\circ}\right)\end{array}$ & $\begin{array}{l}\text { Height } \\
\text { above } \\
\text { sea } \\
\text { level } \\
(\mathrm{m})\end{array}$ & $\begin{array}{l}\text { Annual } \\
\text { average } \\
\text { temperature } \\
\left({ }^{\circ} \mathrm{C}\right)\end{array}$ & $\begin{array}{l}\text { Annual } \\
\text { sunlight } \\
\text { hours }^{\mathrm{a}} \\
(\mathrm{h})\end{array}$ & $\begin{array}{l}\text { Annual } \\
\text { precipitation }^{\mathrm{a}} \\
(\mathrm{mm})\end{array}$ \\
\hline Sapporo & Sapporo & 43 & 141 & 6 & 9.0 & 1749 & 1100 \\
Yamagata & Yamagata & 38 & 140 & 109 & 11.8 & 1631 & 1153 \\
Akishima & Hachioji & 36 & 139 & 96 & 14.4 & 1869 & 1596 \\
Takaoka & Fushiki & 37 & 137 & 3 & 14.0 & 1649 & 2254 \\
Kure & Kure & 34 & 133 & 2 & 16.3 & 2087 & 1383 \\
Kochi & Kochi & 34 & 134 & 7 & 17.0 & 2178 & 2584 \\
Miyazaki & Miyazaki & 32 & 131 & 63 & 17.7 & 2127 & 2562 \\
\hline
\end{tabular}




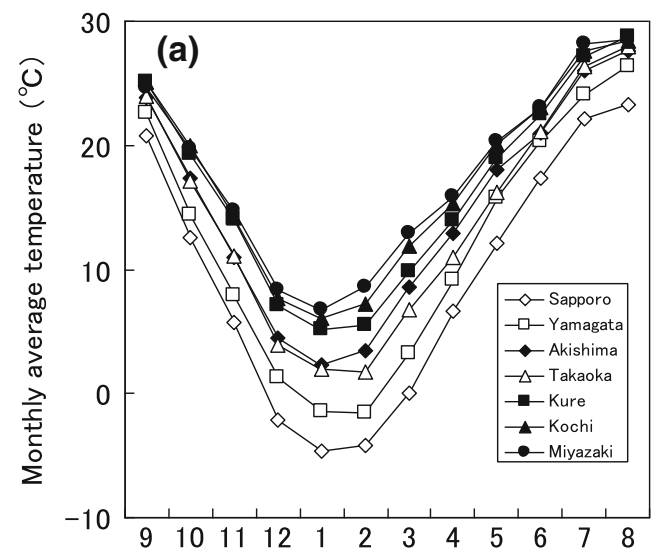

Month (average : September, 2011 - August, 2013)

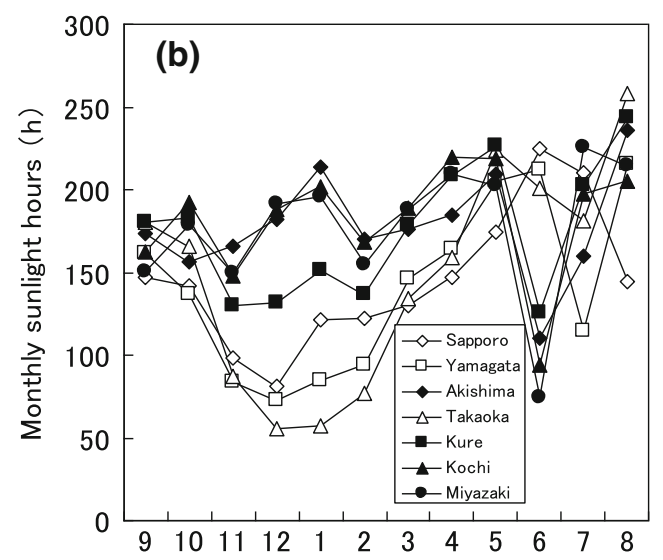

Month (average : September, 2011 - August, 2013)

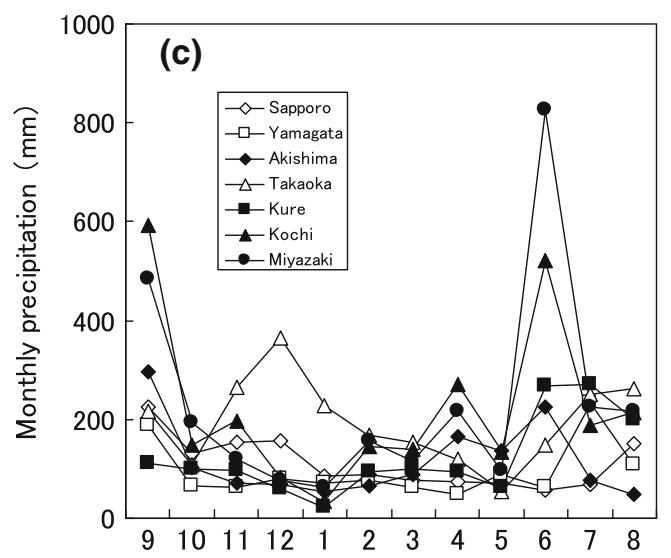

Month (average : September, 2011 - August, 2013)

Fig. 2 Climate conditions at the seven test sites. a Monthly average temperature, $\mathbf{b}$ monthly sunlight hours, $\mathbf{c}$ monthly precipitation

obtained from the Japan meteorological agency observation sites cloth to the test sites. The monthly average temperature, monthly sunlight hours, and monthly precipitation over the two-year test duration are shown in Fig. 2. Average temperatures of the snow sites (Sapporo, Yamagata, and Takaoka) were lower than those of the other sites. Sunlight hours were greater at lower latitudes, with the exception of Yamagata and Takaoka. Yamagata and Takaoka had fewer sunlight hours compared to Sapporo. Takaoka, Kochi, and Miyazaki had high precipitation levels.

The WPCs and PE-RS were set facing the south. Exposure angles were $45^{\circ}$ for Sapporo, Yamagata, Akishima, Takaoka, and Kochi, and to latitude $-10^{\circ}$ for Kure and Miyazaki. The WPCs and PE-RS were placed on a test frame, and the outdoor exposure tests were started on August 24 or 25, 2011, and lasted for 2 years. The WPCs were removed from test rack after $3,6,9,12$, and 24 months of exposure. The PE-RS were exchanged for new specimens every month during the exposure period of 2 years.

\section{Evaluation of chalking}

WPCs surface abrasion tests were used to evaluate the extent of chalking [19]. Abrasion was conducted manually using a finger wrapped in white cloth. Abrasion was carried out once for each specimen, and the distance moved by the finger was set at $80 \mathrm{~mm}$. The pressure of abrasion was approximately $72 \mathrm{kPa}$. The white cloth used was measured for color before and after the abrasion tests, using a spectrophotometer (X-Rite, SP88) that reads $L^{*}, a^{*}$, and $b^{*}$ values in the CIE-LAB system. The color differences $\left(\Delta E^{*} a b\right)$ were calculated using Eqs. (1)-(4).

$\Delta L^{*}=L_{n}^{*}-L_{0}^{*}$

$\Delta a^{*}=a_{n}^{*}-a_{0}^{*}$

$\Delta b^{*}=b_{n}^{*}-b_{0}^{*}$

$\Delta E^{*} a b=\left\{\left(\Delta L^{*}\right)^{2}+\left(\Delta a^{*}\right)^{2}+\left(\Delta b^{*}\right)^{2}\right\}^{1 / 2}$

The number of specimen was two in each exposure test site. The measurement points of the WPCs were set at one point for each specimen, and the means were calculated. The resulting $\Delta E^{*} a b$ values were defined as the extent of chalking [19].

\section{Polyethylene carbonyl index}

Fourier transform infrared spectroscopy (FT-IR) spectra of the PE-RS were obtained by measuring the transmittance (THERMO Scientific, Nicolet 6700 FT-IR), which was then converted to absorbance. All the spectra obtained were the averages of 24 scans at $4 \mathrm{~cm}^{-1}$. Absorbance of the $1715 \mathrm{~cm}^{-1}$ wave number, which corresponds to a carbonyl functional group, and absorbance of the $2020 \mathrm{~cm}^{-1}$, which corresponds to a methylene functional group, were calculated. The polyethylene carbonyl index (PE-CI) was calculated using Eq. (5) and Fig. 3 [17, 18]. 




Fig. 3 Measurement method for the polyethylene carbonyl index (PE-CI) $[17,18]$

PE-CI $=A_{1715} / A_{2020}$

where, $A_{1715}$ is the absorbance of the nearby $1715 \mathrm{~cm}^{-1}$, $A_{2020}$ is the absorbance of the nearby $2020 \mathrm{~cm}^{-1}$. Each absorbance was calculated from Eq. (6).

$A=I-I_{0}$

where, $I$ is the absorbance of each wave number, $I_{0}$ is the absorbance of the base line in each wave number, as shown in Fig. 3.

Analysis of the surface deterioration

\section{Scanning electron microscope (SEM)}

Scanning electron microscope observations were carried out to evaluate the shape of the chalking products. The surfaces of the WPCs exposed outdoors in Yamagata for 12 months (Yamagata 12 months) were placed in contact with conductive tape. The chalking products, which stuck to the tape, were observed using the low vacuum mode of the SEM without metal evaporation (FEI, Quanta400).

\section{Polarization optical microscope (POM)}

Polarization optical microscope observation was carried out to verify the dispersion of wood elements and polyolefin on the surface of the WPCs before and after the outdoor exposure. Films with a thickness of $30 \mu \mathrm{m}$ were cut off from the vertical cross-sections of the extrusion direction of the WPCs [Yamagata 12 months and the original (un-exposed specimen)] using a rotary type microtome. The films were observed using a polarization microscope (Olympus BH2).

\section{Fourier transform infrared spectroscopy analysis}

FT-IR-ATR analysis was carried out to investigate the change in the main functional group on the surface of the
WPCs before and after the outdoor exposure. The surface of the Yamagata 12 months and the un-exposed specimens were measured by FT-IR-ATR (PerkinElmer, Frontier Gold FTIR). All the spectra obtained were the averages of 8 scans at $4 \mathrm{~cm}^{-1}$.

\section{Differential scanning calorimetry analysis (DSC)}

Differential scanning calorimetry analysis was carried out to obtain information on the deterioration of the polyolefins on the surface of the WPCs before and after the outdoor exposure. Films with a thickness of approximately $50 \mu \mathrm{m}$ were cut off from the surface of the WPCs (Yamagata 12 months and the original) with an ultra-microtome, and measured by DSC (PerkinElmer, DSC8500) under a nitrogen atmosphere. The film specimens were heated to $200{ }^{\circ} \mathrm{C}$ at a rate of $10{ }^{\circ} \mathrm{C} / \mathrm{min}$ (1st heating) and kept at that temperature for $3 \mathrm{~min}$. They were then cooled down to $30{ }^{\circ} \mathrm{C}$ at a rate of $10{ }^{\circ} \mathrm{C} / \mathrm{min}$ and kept at that temperature for $3 \mathrm{~min}$. And they were finally heated up to $200{ }^{\circ} \mathrm{C}$ (2nd heating).

\section{Results and discussion}

Results of the outdoor exposure test

\section{Chalking}

Figure 4 shows the extent of chalking for the different specimens. The data from cold areas (Sapporo, Yamagata, and Takaoka) and warm areas (Akishima, Kure, Kochi and Miyazaki) were plotted as outlined symbols and filled symbols, respectively. The color difference of chalking $\left(\Delta E^{*} a b\right)$ continued to increase for up to 1 year of outdoor exposure. After 1 year, $\Delta E^{*} a b$ was saturated. The tendency of $\Delta E^{*} a b$ to change can be compared in the cold areas and the warm areas.

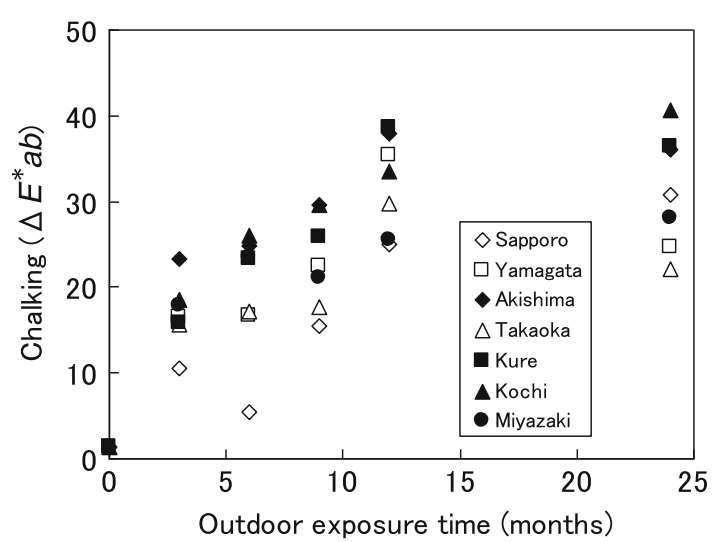

Fig. 4 Comparison of chalking $\left(\Delta E^{*} a b\right)$ among the outdoor exposure test sites. Outlined symbols cold area, filled symbols warm area 

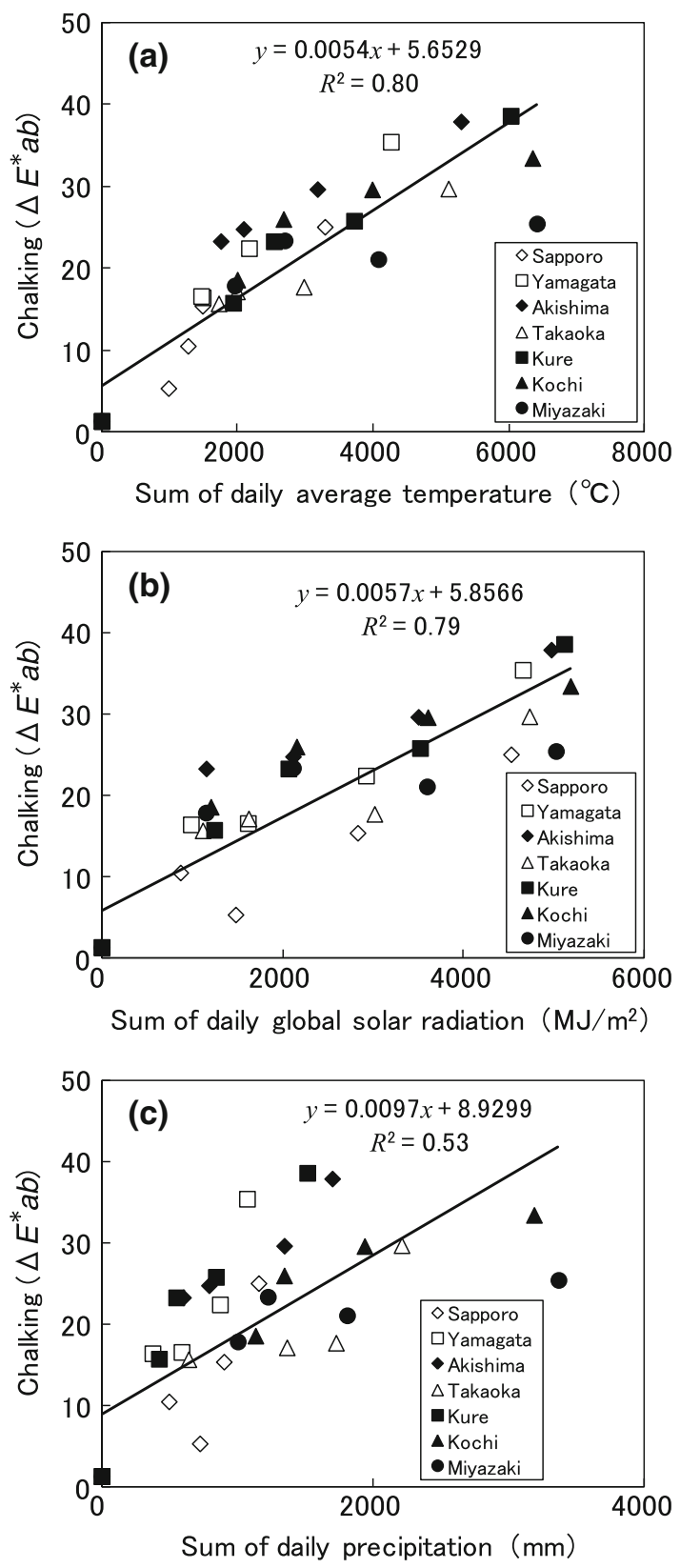

Fig. 5 The relationship between chalking $\left(\Delta E^{*} a b\right)$ and various weather factors during 1 year of outdoor exposure. a Sum of daily average temperatures, $\mathbf{b}$ sum of daily global solar radiation, $\mathbf{c}$ sum of daily precipitation

Figure 5 shows the relationship between $\Delta E^{*} a b$ and various weather factors [(a) sum of daily average temperatures, (b) sum of daily global solar radiation, and (c) sum of daily precipitation] during one year of outdoor exposure. Data from the Japan Meteorological Agency were adopted for each weather condition [20]. Global solar radiation was adopted as a substitute for sunlight hours, as more accurate analytical results can be expected compared to sunlight hours. However, global solar radiation data on Akishima, Takaoka, and Kure did not exist in the database of the Japan
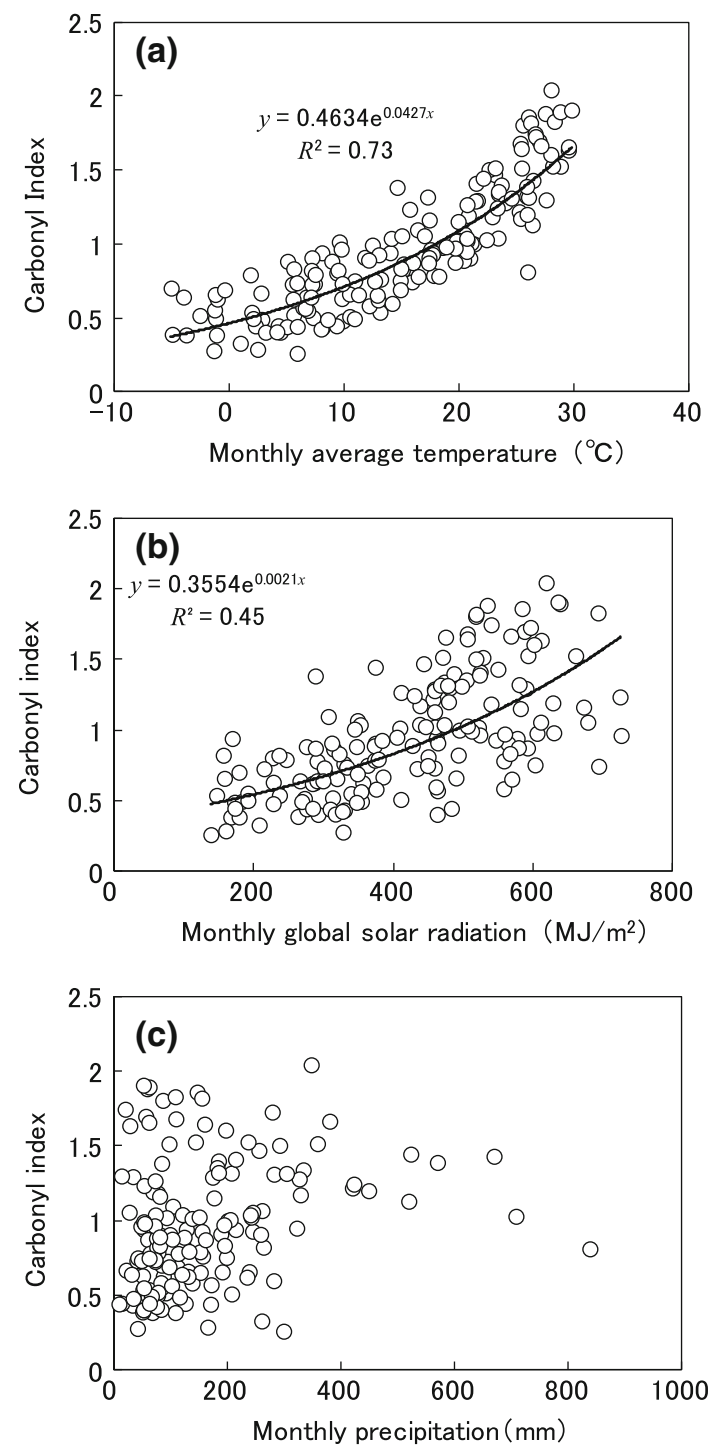

Fig. 6 The relationship between the polyethylene carbonyl index and various weather factors during outdoor exposure for 2 years. a Monthly average temperature, b monthly global solar radiation, c monthly precipitation

Meteorological Agency. Therefore, the global solar radiation for these regions was estimated using the number of sunlight hours and the latitude [21]. Single linear regression analysis was then performed on the data. The coefficients of determination were $0.80,0.79$, and 0.53 for the (a) sum of daily average temperature, (b) sum of daily global solar radiation, and (c) sum of daily precipitation, respectively.

From these results, it was determined that temperature and global solar radiation had the greatest influence on chalking.

\section{Polyethylene carbonyl index}

Figure 6 shows the relationships between the PE-CI and various weather factors during 2 years of outdoor exposure: (a) monthly average temperature, (b) monthly global 


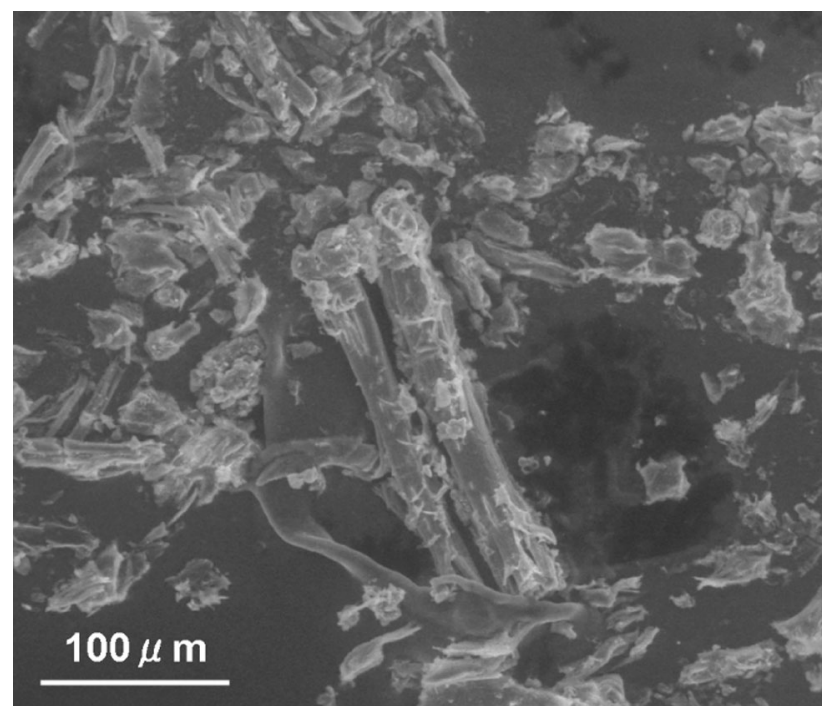

Fig. 7 SEM image of the chalking products generated from the surface of the WPCs (Yamagata 12 months)

solar radiation, and (c) monthly precipitation. A regression curve was applied to the data on PE-CI and the monthly average temperature (Fig. 6a) [22], and the coefficient of determination was 0.73. As shown in Fig. 6b, the PE-CI increased with an increase in global solar radiation, although the coefficient of determination was much lower (0.45) compared to the monthly average temperature. On the other hand, no correlation was found between PE-CI and monthly precipitation (Fig. 6c). From these results, it was found that the temperature had the greatest influence on the oxidative reaction of $\mathrm{PE}$, which suggests that the same effect occurs on polyolefin elements in WPCs.

Analytical results of the surface deterioration layer

\section{SEM}

Figure 7 shows an SEM image of the chalking products of the Yamagata 12 months specimen. Fibrous substances with a length of about $200 \mu \mathrm{m}$ and particulate matter under $50 \mu \mathrm{m}$ in diameter were observed. In a previous study, in which chalking products were measured with IR [16], it was suggested that the chalking products might be composed of wood elements and plastic elements. This SEM image thus showed that both wood elements and plastic elements came from the surface of the WPCs.

\section{POM}

Figure 8 shows POM images of the surface of the WPCs (Yamagata 12 months and the original). Particles that have a light color are polyolefins. Particles that are dark in color
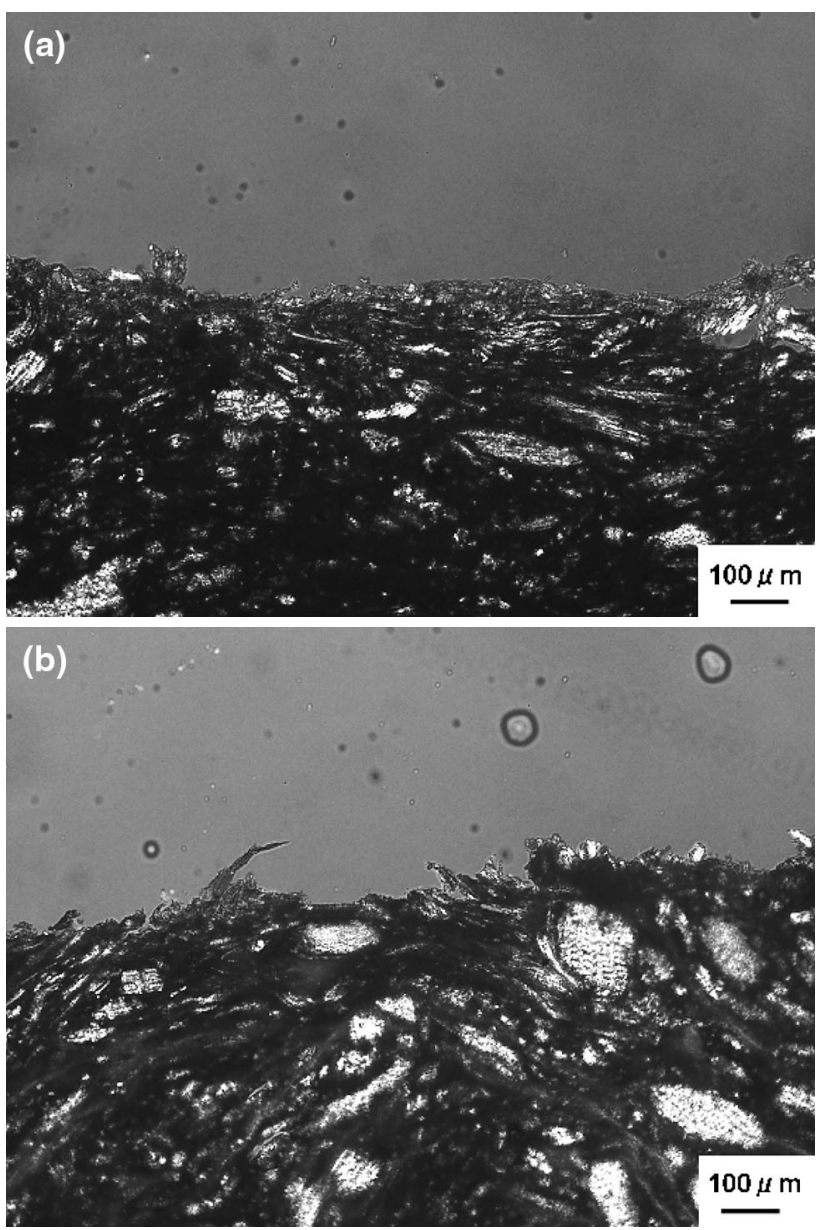

Fig. 8 POM images of the surfaces of the WPCs. a The original, b Yamagata 12 months specimen

were assumed to be wood elements or compound areas consisting of wood and polyolefin elements.

The surface of the original specimen already had some roughness. However, surface roughness increased when subjected to outdoor exposure.

\section{$F T-I R$}

Figure 9 shows FT-IR spectra of the surface of the WPCs (Yamagata 12 months and the original). The peak near $1720 \mathrm{~cm}^{-1}$ increased a little after 1 year of outdoor exposure. This implies that oxidation of both wood and polyolefin occurred [23]. The peak at $1509 \mathrm{~cm}^{-1}$ almost disappeared after outdoor exposure. This implies that degradation of lignin occurred.

DSC

Figure 10 shows DSC 2nd heating curves of the approximately $50 \mu \mathrm{m}$ thick films cut off from the surfaces of the WPCs (Yamagata 12 months and the original). Peaks at 


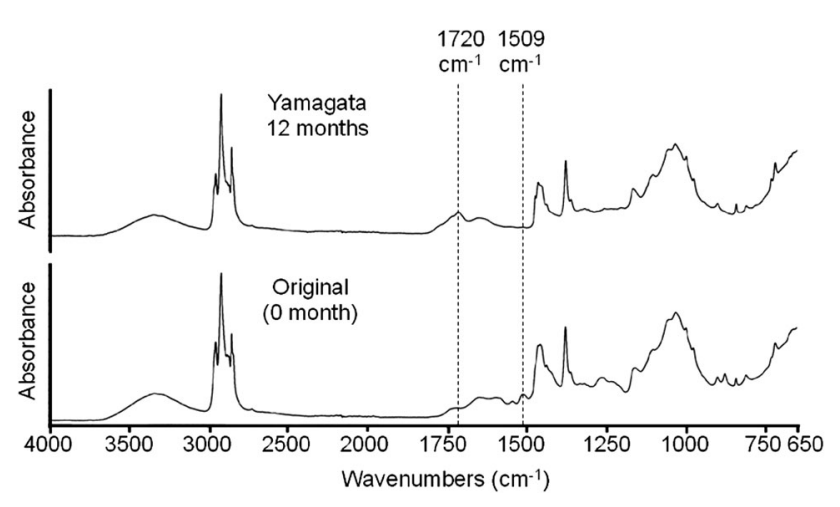

Fig. 9 FT-IR-ATR spectra of the WPCs

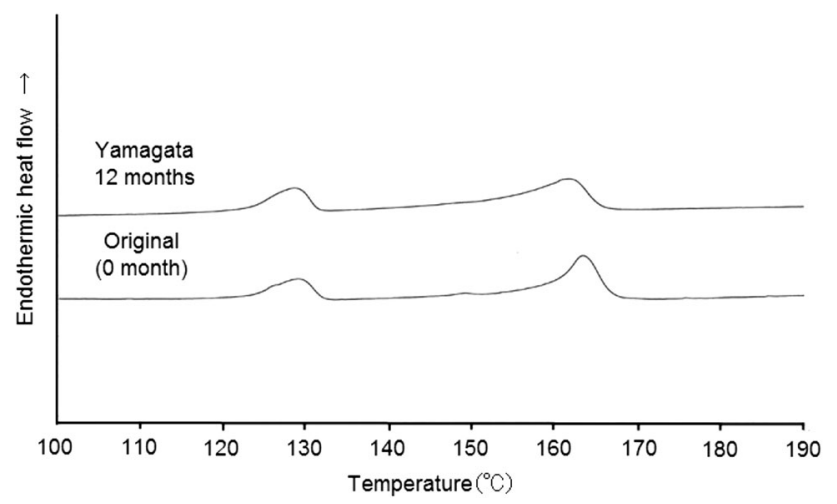

Fig. 10 DSC second heating curves of the WPCs

nearly $129{ }^{\circ} \mathrm{C}$ and $163{ }^{\circ} \mathrm{C}$ correspond to the melting temperature of $\mathrm{PE}$ and $\mathrm{PP}$, respectively. The peak due to the melting of PE was relatively unchanged by outdoor exposure, whereas the peak due to the melting of PP became broader. Furthermore, the peak temperature of PP decreased by $1.6^{\circ} \mathrm{C}$. These results suggest that molecular weight of PP decreased.

Factors responsible for the occurrence of chalking

Factors responsible for the occurrence of chalking were determined from statistical analyses of chalking and PE-CI by various weather factors, and from results of SEM, POM, FT-IR and DSC. Chemical degradation of lignin begins on the surface of WPCs due to outdoor exposure. As for polyolefins, an oxidative reaction occurs in both PE and PP. However, PP deteriorates more easily than PE, and the molecular weight of PP decreases. The bond strength between polyolefin (especially PP) and the wood elements decreases. It has already been shown that separation products are easily formed from the surface of WPCs before outdoor exposure by surface sanding. In addition, the surface of WPCs becomes rougher due to outdoor exposure. Therefore, it is believed that chalking occurs due to the combined effect of the deterioration reaction and the sanding process when an abrasive force is added to the surface.

Temperature and global solar radiation have the greatest influence on the occurrence of chalking. These are likely to be because the oxidation reaction on the surface of WPCs is more susceptible to temperature and chemical degradation of lignin and a decrease of the molecular weight of PP is more susceptible to global solar radiation.

There was almost no difference in the amount of chalking between 1 and 2 years of exposure (Fig. 4). A similar saturation phenomenon was reported in a previous study on the change in oxygen content on the surface of a Japanese lacquer film, as measured by an outdoor exposure test [24]. The oxides were gradually eroded off the surface of the Japanese lacquer film due to wind and rain [24]. Therefore, it is assumed that the same phenomenon may have occurred in the case of the WPCs. Initially, the amount of oxides eroded by the wind and rain in the absence of frictional forces increased after an exposure period of 1 year. Next, deterioration began in the areas where the oxides were eroded by wind and rain, which resulted in new chalking products on the surface. Finally, the amount of chalking measured by frictional examination settled down to a certain fixed value.

\section{Conclusions}

Outdoor exposure tests of WPCs were carried out at seven sites in Japan, and chalking on the surface of the WPCs was examined. It was determined that deterioration of wood elements, oxidation of polyolefins, and a decrease in the molecular weight of PP occurred on the surface of the WPCs. Surface sanding of the WPCs also promoted the occurrence of chalking. Furthermore, the results of a single regression analysis indicated that temperature and global solar radiation were the most dominant weather factor influencing chalking. In addition, chalking products can be washed away to a certain extent due to precipitation.

Acknowledgments This study was supported by the Council of Promotion for Industrial Technology Collaboration, Nanotechnology and Materials committee, Polymer subcommittee. The authors wish to thank Mr. Akihiro Oishi of National Institute of Advanced Industrial Science and Technology for the measurement of the FT-IR spectra of PE-CI, and Dr. Takashi Kuriyama of Yamagata University for valuable discussions and his assistance in taking the POM images. We express our gratitude to Dr. Koetsu Takahashi of Yamagata University and Dr. Hisayoshi Kofujita of Iwate University for their valuable comments. We also thank Mr. Katsumi Konno and Mr. Takashi Oichi of Hokkaido Research Organization Industrial Technology Research Department, Dr. Takeshi Yasuda and Dr. Kenichi Shimizu of Tokyo Metropolitan Industrial Technology Research Institute, Mr. Wataru Mizuno of Toyama Industrial Technology Center, Mr. Kimitaka Tahira of Hiroshima Prefectural Technology Research Institute 
Western Region Industrial Research Center, Dr. Nozomu Tsuruta of Kochi Prefectural Industrial Technology Center, and Mr. Shingo Hamayama of Miyazaki Prefecture Industrial Technology Center, for their cooperation in the outdoor exposure tests.

\section{References}

1. Takatani M, Okamoto T (2008) Fundamental and application of cellulose materials: wood plastic composite (in Japanese). J Soc Mater Sci Jpn 57:415-420

2. Rowell RM (2007) Challenges in biomass-thermoplastic composites. J Polym Environ 15:229-235

3. Okamoto T (2003) Recent developments in wood/plastic composites: extrusion of wood-based materials (in Japanese). Mokuzai Gakkaishi 49:401-407

4. Kikuchi T (2012) The market trend of wood plastic composites (in Japanese). Mokuzai Kogyo 67:475-477

5. Pendlton DE, Hoffard TA, Adcock T, Woodward B, Wolcott MP (2002) Durability of an extruded HDPE/wood composite. Forest Prod J 52:21-27

6. Kiguchi M, Kataoka Y, Matsunaga H, Momohara I, Kawamoto S, Ohtomo Y (2010) Durability of woodflour-plastic composites (1) Influence of woodflour content on water resistance (in Japanese). Mokuzai Hozon (Wood preservation) 36:52-58

7. Kiguchi M, Kataoka Y, Matsunaga H, Momohara I, Kawamoto S, Kobayashi M, Ohtomo Y (2010) Durability of woodflour-plastic composites (2) Evaluation of decay resistance by soil-buried test (in Japanese). Mokuzai Hozon (Wood preservation) 36:150-157

8. Wang W, Morrell JJ (2004) Water sorption characteristics of two wood-plastic composites. Forest Prod J 54:209-212

9. Stark NM (2006) Effect of weathering cycle and manufacturing method on performance of wood flour and high-density polyethylene composites. J Appl Polym Sci 100:3131-3140

10. Stark NM, Matuana LM (2006) Influence of photostabilizers on wood flour-HDPE composites exposed to xenon-arc radiation with and without water spray. Polym Degrad Stab 91:3048-3056

11. Stark NM, Matuana LM (2007) Characterization of weathered wood-plastic composite surfaces using FTIR spectroscopy, contact angle, and XPS. Polym Degrad Stab 92:1883-1890

12. Kojima Y, Shimoda T, Suzuki S (2011) Evaluation of the weathering intensity of wood-based panels under outdoor exposure. J Wood Sci 57:408-414
13. Kojima Y, Shimoda T, Suzuki S (2012) Modified method for evaluating weathering intensity using outdoor exposure tests on wood-based panels. J Wood Sci 58:525-531

14. Sekino N, Sato H, Adachi K (2014) Evaluation of particleboard under outdoor exposure using several different types of weathering intensity. J Wood Sci 60:141-151

15. Ohshima A, Furuta Y (2010) Study on long-term durability of WPRC. Correlation of outdoor weathering and accelerating test (in Japanese). Summaries of technical papers of annual meeting architectural institute of Japan. Materials and construction, Toyama, pp 551-552

16. Kiguchi M, Kataoka Y, Matsunaga H, Yamamoto K, Evans PD (2007) Surface deterioration of wood-flour polypropylene composites by weathering trials. J Wood Sci 53:234-238

17. JWTCS 4001 (2009) Polyethylene reference specimen for weathering test. Japan Weathering Test Center Standard, Japan Weathering Test Center, Tokyo

18. JWTCS 4002 (2009) Evaluating method of weathering conditions for plastics using polyethylene reference specimens. Japan Weathering Test Center Standard, Japan Weathering Test Center, Tokyo

19. Kiguchi M, Kataoka Y, Kobayashi M, Kawamoto S, Matsunaga $\mathrm{H}$, Ohtomo Y (2011) Decreasing the incidence of chalking of weathered wood flour polypropylene composites by UVA and HALS. In: Proceedings of 5th international wood fibre polymer composites symposium, Biarritz, pp 1-10

20. Japan Meteorological Agency website. http://www.jma.go.jp/ jma/index.html. Accessed 29 Oct 2013

21. Kuwagata $T$ (2006) http://cse.naro.affrc.go.jp/ketanaka/model/ help/solarradiation/kuwagata/ame_sd.pdf. Accessed 10 March 2014

22. Konno K (2010) Interrelations between weather conditions and carbonyl index using standard reference test specimens for expose apparatus (in Japanese). Reports of Hokkaido Research Organization Industrial Research Institute 309:155-159

23. Murayama M, Yano S (1988) Photodegradation of polypropylene films using spectrally dispersed light (in Japanese). Kobunshi Ronbunshu 45:789-793

24. Ogawa T (2014) Science of the Japanese lacquer (in Japanese). Kyoritsu Shuppan, Tokyo, pp 49-57 